\title{
Desafios e perspectivas de um Programa de Pós-Graduação em Psicologia de uma instituição privada no Nordeste brasileiro
}

Normanda Araujo de Morais. Universidade de Fortaleza

Luana Elayne Cunha de Souza. Universidade de Fortaleza

Luciana Maria Maia. Universidade de Fortaleza

Leônia Cavalcante Teixeira. Universidade de Fortaleza

\section{Resumo}

Busca-se apresentar o Programa de Pós-graduação em Psicologia (PPG-Psi) da Universidade de Fortaleza (Unifor), discutindo desafios e perspectivas da sua existência, enquanto um programa de uma instituição privada, no Nordeste brasileiro. Para tanto, foram realizados dois estudos empíricos: o primeiro traçou um panorama das pesquisas desenvolvidas no programa; e o segundo analisou as percepções dos professores do programa acerca dos desafios que enfrentam no cotidiano de trabalho docente. Os resultados indicaram a pluralidade teórica e metodológica que constitui o PPG-Psi, ilustrada nos títulos de dissertações e teses; e que os principais desafios citados pelos docentes referem-se ao imperativo econômico que rege as instituições de ensino superior privadas e ao preconceito sofrido. As boas condições de trabalho e as especificidades de atuação na Unifor também foram citadas. As perspectivas futuras foram descritas com base em ações internas e externas ao PPG-Psi, valorizando a produção acadêmico-científica e a relevância social e política delas.

Palavras-chave: pós-graduação; instituição privada; Psicologia.

\begin{abstract}
Challenges and Perspectives of a Psychology Postgraduate Program of a Private Institution in Northeast Brazil. The aim is to present the Postgraduate Program in Psychology (PPG-Psi) of the University of Fortaleza (Unifor), discussing challenges and perspectives of its existence, as a program of a private institution located in northeastern Brazil. Therefore, two empirical studies were performed: the first outlined the research carried out in the program and the second analyzed the teachers' perceptions of the program about the challenges they face in their daily teaching work. The results indicated the theoretical and methodological plurality that constitutes the PPG-Psi, illustrated in the titles of dissertations and theses; and that the main challenges cited by the teachers refer to the economic imperative that governs private higher education institutions and the prejudice suffered. The good working conditions and specificities of work at Unifor were also mentioned. The future perspectives were described based on internal and external actions to PPG-Psi, valuing the academic-scientific production and, above all, their social and political relevance.
\end{abstract}

Keywords: postgraduate; private institution; Psychology.

\section{Resumen}

Desafíos y Perspectivas de un Programa de Posgrado en Psicología de una Institución Privada en el nordeste brasileño. Se busca presentar el Programa de Posgrado en Psicología (PPG-Psi) de la Universidad de Fortaleza (Unifor), al discutir los desafíos y perspectivas de su existencia, posgrado de una institución privada de enseñanza superior, en el nordeste brasileño. Por lo tanto, se realizaron dos investigaciones empíricas: en la primera se estructuró un panorama de las investigaciones desarrolladas en el programa de posgrado; en la segunda se conoció las percepciones de los profesores del programa de posgrado sobre los desafíos que estos enfrentan en sus trabajos diarios. Los resultados indicaron la pluralidad teórica y metodológica que constituye el PPG-Psi, ilustrada en los títulos de los trabajos de fin de máster y tesis doctoral; y que los principales desafíos citados por los docentes se refieren, sobre todo, al imperativo económico que rige las instituciones privadas de educación superior y al prejuicio sufrido por ellos. Las buenas condiciones de trabajo y las especificidades de actuación en la Unifor también fueron indicadas. Las perspectivas de futuro fueron descritas en función de acciones internas y externas al PPG-Psi, valorando la producción.

Palabras-clave: posgrado; institución privada; Psicología. 
O Programa de Pós-graduação em Psicologia (PPG-Psi) da Universidade de Fortaleza (Unifor) foi criado em 1997, como Curso de Mestrado em Psicologia e Subjetividade, destacando a saúde e a cultura como prioridades, de acordo com as ações do Ministério da Ciência e Tecnologia, através da Coordenação de Aperfeiçoamento de Pessoal de Nível Superior (CAPES), e em conjunto com o governo do estado do Ceará, representado pela Fundação Cearense de Amparo à Pesquisa (FUNCAP). Essas ações aconteceram no âmbito do Projeto Nordeste de Pesquisa e Pós-Graduação, tendo em vista minimizar as disparidades regionais vividas pelos programas, frente a um sistema com alto nível de concentração de cursos nas regiões Sul e Sudeste, visando consolidar uma política e fomentar uma cultura de pós-graduação no Nordeste.

Desse modo, desde 1995, a Comissão para Estudos de Implantação e Implementação do Mestrado em Psicologia na Unifor (CEIMP), composta pelos professores Clara Pinheiro, Maria Celina Peixoto, Georges Boris e Leônia Teixeira, foi responsável pela elaboração da proposta inicial do curso, seguindo as diretrizes da CAPES. Os cursos de especialização "Filosofia e Epistemologia em Psicologia"; "Psicologia Educacional", "Educação e Saúde Pública"; e "Psicomotricidade", que compunham a pós-graduação latu sensu da Unifor, favoreceram a demanda por um curso de pós strictu sensu que acolhesse a demanda do contingente de profissionais já formados no Estado e região. Na construção do mestrado, foram priorizadas as demandas de psicólogos no Ceará e região NorteNordeste, já que poucos cursos existiam à época, bem como as diretrizes da CAPES quanto à inserção social e à formação de recursos humanos para a pesquisa e para a docência.

Tourinho e Bastos (2010), ao abordarem a construção da pós-graduação no Brasil, ressaltam a importância do Parecer Newton Sucupira (Conselho Federal de Educação, Parecer 977, de 03/12/1965), no qual "a realização dos fins essenciais da universidade" é relacionada à pós-graduação strictu sensu. Esta, por sua vez, "é de natureza acadêmica e de pesquisa e mesmo atuando em setores profissionais tem objetivo essencialmente científico, enquanto a especialização, via de regra, tem sentido eminentemente prático-profissional; [a pós-graduação stricto sensu] confere grau acadêmico e a especialização confere certificado" (Tourinho \& Bastos, 2010, p. 36).
Com o propósito de se estabelecer como um curso de referência na região, a primeira turma de mestrandos do PPG-Psi Unifor contou com disciplinas ministradas pelos professores Luís Cláudio Figueiredo (USP/ PUC), Mauro Martins Amatuzzi (USP/ PUC-Campinas), Benilton Bezerra Jr. (UERJ) e William Gomes (UFRGS). $E$, além disso, de forma pioneira, nos primeiros anos de implementação do mestrado, houve a criação da Revista Mal-Estar e Subjetividade, hoje Revista Subjetividades, e realizou-se o Congresso Mal-Estar e Subjetividade, que reuniu nomes de relevância nacional e internacional da pesquisa em Psicologia.

Em 2010, como resultado do processo de desenvolvimento e qualificação, bem como da aceitação e reconhecimento regional e nacional do curso de mestrado, teve início o Curso de Doutorado em Psicologia da Unifor, também pioneiro no Estado do Ceará. Com a consolidação do curso de Mestrado, a urgência de implantação do Curso de Doutorado se forjou, especialmente mobilizada pelos impactos regionais das produções dos mestrandos egressos e de novas ambições daí decorrentes quanto à carreira acadêmica. Esse processo foi conduzido pelo professor Henrique Figueiredo Carneiro, que estava à frente da coordenação do mestrado na ocasião, em parceria com o corpo docente do curso.

A importância de diagnósticos das lacunas e potencialidades visando a uma agenda de ações concretas de médio e longo prazos, para o fortalecimento da Pós-Graduação em Psicologia no Brasil é ratificada por diversos autores (Féres-Carneiro, Bastos, Feitosa, Seidl-de-Moura, \& Yamamoto, 2010; Tourinho \& Bastos, 2010; Yamamoto, 2006; Yamamoto \& Tourinho, 2007). Assim, seguindo o que preconizava o Plano Nacional de Pós-Graduação 2005-2010 (CAPES, 2004), o programa de Pós-Graduação em Psicologia (Mestrado e Doutorado) da Unifor supriu lacunas históricas na expansão da Pós-Graduação no país, marcada, ainda hoje, pela assimetria entre as regiões, com número insuficiente de cursos strictu sensu nas regiões Norte, Nordeste e CentroOeste (Tomanari, Santos, \& Mourão, 2019).

Em 2017, o programa completou 20 anos de fundação. E, em 2019, conta com um corpo docente de 14 professores permanentes e um professor colaborador. Ao longo dessa história, o PPG-Psi contabiliza 385 dissertações defendidas e 46 teses. O Programa tem sua estrutura de funcionamento nos Laboratórios, os quais funcionam como o lócus de sustentação da 
pesquisa, ensino e extensão no âmbito da pós-graduação no PPG-Psi. Os laboratórios contam com a coordenação de um (ou mais) docente(s) permanente(s) do Programa e com a participação de integrantes de diferentes níveis de formação - alunos de iniciação científica (bolsistas e voluntários), mestrandos, doutorandos, docentes permanentes, colaboradores e outros docentes vinculados apenas aos cursos de graduação da Unifor, por exemplo. Atualmente, o Programa conta com 08 laboratórios, a saber: APHETO - Laboratório de Psicopatologia e Clínica Humanista-Fenomenológica; LAEPCUS - Laboratório de Estudos Sobre Psicanálise Cultura e Subjetividade; LEPES - Laboratório de Estudos sobre Processos de Exclusão Social; LEPP-Saúde Laboratório de Estudos e Práticas em Psicologia e Saúde; LERHA - Laboratório de Estudos das Relações Humano-Ambientais; LESPLEXOS - Laboratório de Estudos dos Sistemas Complexos: Casais, Famílias e Comunidade; LET - Laboratório de Estudos do Trabalho; e OTIUM - Laboratório de Estudos sobre Ócio, Trabalho e Tempo Livre.

Seguindo os ventos da pós-graduação no Brasil, a abrangência de temáticas abordadas pelas áreas de concentração e linhas de pesquisa, bem como coordenação das professoras Tereza Rocha Matos, de 2012 a 2015, e Normanda Araujo de Morais, que está à frente desde 2015, o PPG-Psi passou por algumas transformações. Um primeiro processo culminou com as mudanças de nome e de editoria da Revista Mal-Estar e Subjetividade, passando a ser intitulada Subjetividades (em 2014), ampliando as possibilidades de publicação, contemplando diferentes áreas da psicologia, além de agilizar e modernizar o processo de publicação, com avaliação B1 pela Capes.

Dando continuidade, no quadriênio que está em andamento (2017-até o momento presente), o PPG-Psi tem vivenciado mudanças importantes na sua estrutura. Essas mudanças foram impulsionadas, a nível macro, pela política de pós-graduação no país, pelos resultados de avaliações anteriores (2013-2016) e, internamente, por todas as mudanças vividas ao longo dos 20 anos de existência, com ênfase no processo de renovação do quadro docente, atendendo à demanda no aumento do quantitativo de docentes. Consequentemente, essas mudanças levaram ao aumento do número de laboratórios de pesquisa, redefinição das áreas e linhas de pesquisa e reformulação da grade de disciplinas.

Sobre esse processo, inicialmente, o PPG-Psi estava estruturado em duas áreas de concentração:
(1) Estudos Psicanalíticos e (2) Psicologia, Sociedade e Cultura, as quais se subdividiam em três linhas de pesquisa: (1) Sujeito, sofrimento psíquico e contemporaneidade, (2) Produção e expressão sociocultural da subjetividade e (3) Ambiente, trabalho e cultura nas organizações sociais. Com a reformulação, atualmente, o PPG-Psi encontra-se estruturado em uma área de concentração de estudos (Psicologia) e três linhas de pesquisas; (1) Clínica, psicopatologia e processos de subjetivação, (2) Processos de trabalho e saúde, e (3) Processos psicossociais e relação pessoa-ambiente. Ademais, a busca pela amplitude da formação teórica e metodológica resultou em uma recente mudança no currículo do Programa, favorecendo a oferta de disciplinas com foco na diversidade de métodos de pesquisa em Psicologia, na formação para a docência no ensino superior e no aprofundamento de temáticas relacionadas a cada linha de pesquisa.

\section{Características Importantes do PPG-Psi Unifor}

Dentre algumas características importantes do programa, destacam-se: a variedade de temáticas que estuda (psicanálise, fenomenologia, psicopatologia, trabalho, ócio, processos de exclusão social, relações humano-ambientais, famílias e saúde); a diversidade do corpo docente, que possui distintas filiações teóricas e metodológicas; e a diversidade do corpo discente, oriundo de diferentes áreas de conhecimento (por exemplo, Psicologia, Administração, Pedagogia, Jornalismo, Arquitetura, dentre outras). Enfatiza-se a formação de pesquisadores e docentes de instituições de diferentes estados do Nordeste. Quanto ao corpo docente, destaca-se por ser constituído, essencialmente, por pesquisadores do Nordeste, formados em outros estados ou regiões do Brasil, mas que reconhecem na Unifor uma instituição para desenvolvimento e investimento de suas carreiras de pesquisadores.

Além disso, ressalta-se o investimento do PPG-Psi em estimular a formação de novas redes de pesquisa/intervenção e o fortalecimento das redes existentes, envolvendo parcerias nacionais e internacionais, como por exemplo: Rede Internacional de Estudos sobre Ócio, Rede Internacional Coletivo Amarrações - Psicanálise e políticas com juventudes, Movimento Cada Vida Importa - a universidade na prevenção e enfrentamento da violência no Ceará; assim como a divulgação da produção científica em 
periódicos situados nos estratos melhor qualificados (A1-A2 e B1), dados já apresentados em avaliações anteriores da Capes (2013-2016, por exemplo). Avaliado com a Nota 4 naquele quadriênio, o PPG-Psi se diferenciava qualitativamente dos demais cursos com nota semelhante à sua, pela maior qualificação da sua produção. Sobre esse aspecto, vale mencionar o incentivo e subsídio oferecido pela instituição para o custeio de traduções e/ou taxas de publicações em periódicos nacionais e internacionais.

Sublinha-se o percentual de docentes do PPG-Psi com Bolsa Produtividade em Pesquisa do Conselho Nacional de Desenvolvimento Científico e Tecnológico (CNPq), já que $36 \%$ do corpo docente permanente $(n=5)$ possuem bolsas em andamento. No tocante ao financiamento de projetos de pesquisa, citam-se sete em andamento (em 2019), financiados pelo CNPq (Edital Universal; $n=2$ ), pelo Ministério da Saúde e FUNCAP (PPSUS; $n=1$ ); pela CAPES e FUNCAP (Estímulo à Cooperação Científica e Desenvolvimento da Pós-Graduação; $n=1$ ) e pela Fundação Edson Queiroz (FEQ), fundação mantenedora da Unifor (Programa de Apoio a Equipes de Pesquisa; $n=3$ ). Reconhece-se o papel de destaque exercido pelos financiamentos recebidos pelas agências nacionais e locais para o fomento das pesquisas do PPG-Psi e, nos últimos anos, em especial, a importância decisiva dos editais de pesquisa promovidos pela FEQ, sobretudo se considerando a retração dos financiamentos públicos de pesquisa.

Todos os docentes do Programa estão vinculados a algum Grupo de Trabalho (GT) da Associação Nacional de Pesquisa e Pós-Graduação em Psicologia (ANPEPP), sendo pelo menos dois deles coordenados ou vice-coordenados por docentes do PPG-Psi. É importante sublinhar o papel que os GTs da ANPEPP têm desempenhado, em praticamente todas as subáreas da Psicologia, na consolidação de laços e relações entre programas e entre pesquisadores, com forte impacto na produção científica nacional.

O significativo número de profissionais egressos do Programa em outras IES, seja na cidade de Fortaleza, quanto em cidades do interior do Estado do Ceará e até em outros estados da região Nordeste, merece ser destacado, corroborando a relevância social do PPG-Psi na qualificação de recursos humanos para a docência no ensino superior. Um levantamento realizado pela coordenação do Programa em março de 2019 (via consulta ao Currículo Lattes, bem como aos docentes ex-orientadores dos mesmos), visando identificar a situação dos egressos do Programa (23 alunos mestrandos e 11 doutorandos que concluíram em 2018), revelou que a docência é a segunda principal atividade exercida pelos mestrandos, perdendo para a psicologia clínica; e a primeira principal atividade exercida pelos doutorandos. Vale mencionar, porém, que o percentual de mestrandos egressos envolvidos na docência já foi superior em levantamentos anteriores, justificando-se, sobretudo, pelo aumento de demissões nas IES privadas realizadas nos anos de 2017 e 2018.

Finalizando a listagem de características marcantes do PPG-Psi, cita-se a vocação do Programa para o desenvolvimento de um olhar sensível às problemáticas regionais/nacionais, marcadas por situações advindas da gritante desigualdade econômica e social que estão na base de uma série de problemáticas que constituem tema de interesse e pesquisa de docentes e discentes do PPG-Psi. Dentre estas, citam-se: violência, mobilidade urbana, preconceito e exclusão social de minorias sociais (mulheres, população LGBT, indígenas, pessoas com deficiência, etc), inserção precária no trabalho e consequências para a saúde do trabalhador, desenvolvimento humano em contextos de vulnerabilidade social (situação de rua, acolhimento institucional, medidas socioeducativas), saúde mental, dentre outras.

Cabe destacar que essas especificidades do PPG-Psi se tornam ainda mais relevantes quando se considera que se trata de uma instituição privada. No Coleta de 2013-2016, dos 79 programas stricto-senso acadêmicos avaliados, apenas 20 eram de instituições privadas, sendo a maioria $(n=14)$ vinculada a instituições privadas/confessionais. Quanto aos programas stricto-senso profissionais, dos cinco cursos avaliados, três estavam vinculados a instituições privadas. No Nordeste, por sua vez, àquela época, existiam três cursos privados: Universidade Católica de Pernambuco (Unicap) e Universidade de Fortaleza (Unifor), ambas com mestrado e doutorado acadêmico; além da Universidade Potiguar (UnP), com um curso de mestrado profissional. Vale salientar que dentre os 20 programas acadêmicos de instituições privadas, a maioria ( $n=9 ; 45 \%)$ foi avaliada com nota 4 ; seguida de 6 programas (30\%) avaliados com nota 5; 3 (15\%) com nota 3; 1 (5\%) com nota 6; e $1(5 \%)$ com nota 7 (Bastos, Tomanari, \& Trindade, 2017). 
A este respeito, considera-se importante discutir a existência do PPG-Psi a partir dessa característica que lhe é peculiar, qual seja, a sua natureza privada, por se entender que tal fato lhe traz especificidades de funcionamento que precisam ser consideradas quando se pensa a sua inserção no cenário da pós-graduação brasileira. Neste sentido, o objetivo geral do presente trabalho foi apresentar o Programa de Pós-graduação em Psicologia (PPG-Psi) da Universidade de Fortaleza (Unifor), discutindo desafios e perspectivas da sua existência, enquanto um programa de uma instituição privada, no Nordeste brasileiro. Para tanto, foram realizados dois estudos empíricos.

\section{Estudo 1. Panorama das pesquisas desenvolvidas no PPG-Psi: análise dos títulos das dissertações e teses}

Este primeiro estudo teve como objetivo traçar um panorama das pesquisas desenvolvidas no PPG-Psi a partir da análise dos títulos das dissertações e teses defendidas.

\section{Método}

\section{Amostra}

Fizeram parte da amostra os títulos de todas as dissertações e teses defendidas no PPG-Psi até maio de 2019. Especificamente, os títulos de 385 dissertações e 46 teses formaram o corpus de análise da pesquisa.

\section{Procedimento de Coleta dos Dados}

Os títulos dos trabalhos foram retirados do site da Unifor, nas abas Mestrado em Psicologia e Doutorado em Psicologia, respectivamente, e, por sua vez, nas abas Dissertações Defendidas ${ }^{1}$ e Teses Defendidas ${ }^{2}$. A busca foi realizada no mês de junho de 2019.

\section{Procedimento de Análise dos Dados}

Os títulos foram analisados em conjunto por meio de uma Análise Léxica, com auxílio do software para análise de dados textuais IRAMUTEQ (Interface de $R$ pour les Analyses Multidimensionnelles de Textes et de Questionnaires), sendo utilizada a Classificação Hierárquica Descendente (CHD). Para preparação do corpus de análise, foram seguidos os procedimentos recomendados por Camargo e Justo (2018). Os títulos das dissertações e teses foram copiados para um único arquivo de texto e dispostos em uma linha de comando composta por: (1) tipo de trabalho, sendo 1 para dissertações e 2 para teses; e (2) ano da defesa (por exemplo: $* * * * *$ tip_1 *ano_2018 investigando a resiliência em famílias de crianças autistas). Além disso, foi realizada uma revisão textual no corpus, e palavras cujo sentido deveria ser tomado em conjunto foram apresentadas com um underline (por exemplo: abordagem_centrada_ na_pessoa, centro_dia).

Devido às características do corpus e seguindo as instruções de Camargo e Justo (2018), o método de construção do segmento de texto definido foi "parágrafos" e na CHD a opção foi "simples sobre texto". Em relação às formas de palavras ativas e suplementares, foram seguidos os parâmetros padrões do programa, com exceção dos advérbios que passaram da forma ativa para suplementar.

\section{Resultados e discussão}

O corpus total foi composto por 431 segmentos de texto (ST), provenientes de 385 dissertações e 46 teses, com aproveitamento de 365 ST (84,69\%). Emergiram 5.696 ocorrências (palavras, formas ou vocábulos), sendo 1.528 palavras distintas e 997 palavras que apareceram uma única vez. O conteúdo analisado foi categorizado em cinco classes. Essas cinco classes encontram-se divididas em três ramificações ( $A, B$ e $C$ ) do corpus total da análise. O subcorpus A, denominado "Processos Psicossociais", contém os discursos correspondentes à Classe 1 ("Estudos sobre tempo, envelhecimento, família e ambiente") e à Classe 4 ("Estudos sobre Trabalho"). O subcorpus B, denominado de "Psicanálise e Subjetividade", contempla a Classe 2 ("Estudos em Psicanálise") e a Classe 3 ("Estudos sobre modos de subjetivação"). O subcorpus C, denominado de "Fenomenologia Clínica", é composto pela Classe 5 ("Estudos sobre Fenomenologia Clínica").

Sobre as relações entre as cinco classes, pode-se observar que as classes 1 e 4, que formam o subcorpus "Processos Psicossociais", estão relacionadas e se opõem às classes 2 e 3 , que formam o subcorpus "Psicanálise e Subjetividade". Em oposição a essas quatro classes, encontra-se a classe 5 , relativa ao subcorpus "Fenomenologia Clínica". O dendrograma referente a essa análise pode ser observado na Figura 1 


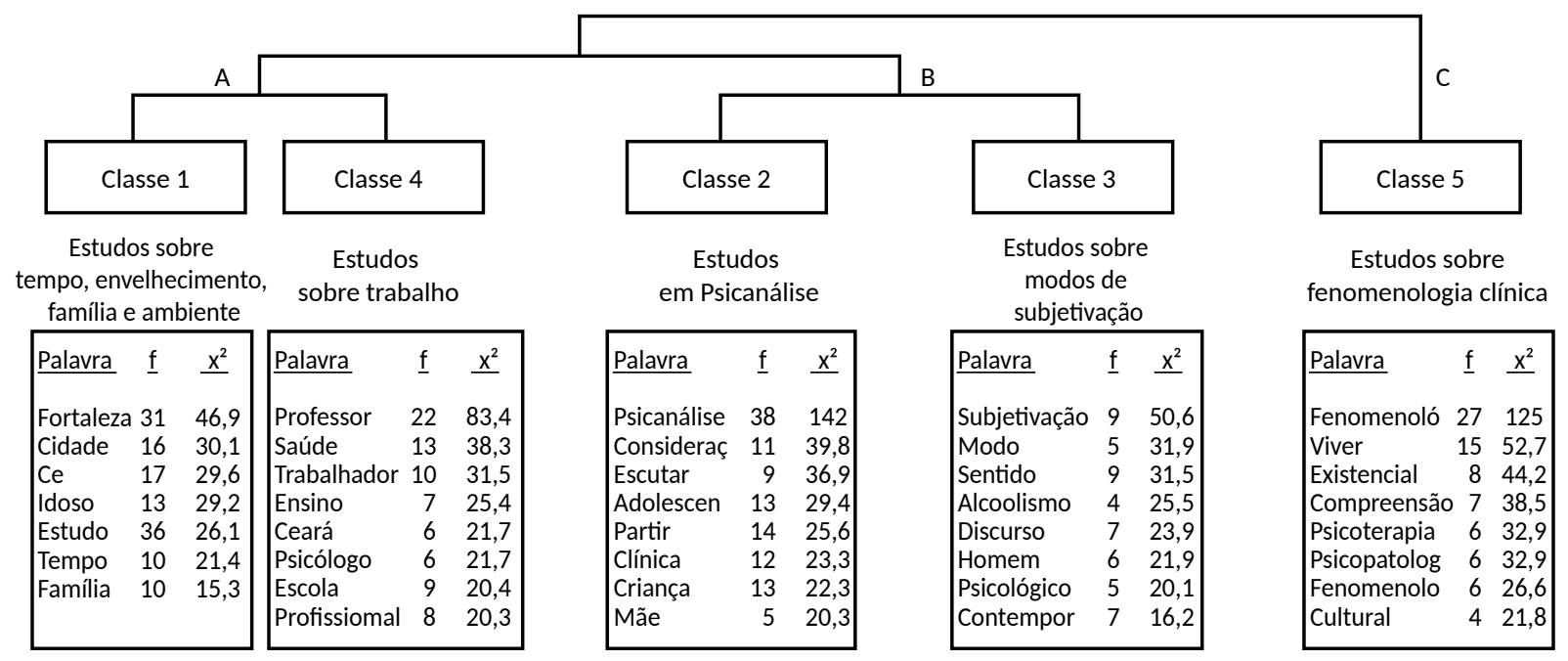

Figura 1. Dendrograma da Classificação Hierárquica Descendente dos trabalhos do PPG-Psi.

\section{Classe 1 - Estudos sobre Tempo, Envelhecimento, Família e Psicologia Ambiental}

Esta classe compreende 28,8\% (105 ST) do corpus total analisado. Constituída por palavras e radicais no intervalo entre $\chi^{2}=47,0$ (Fortaleza) e $\chi^{2}=4,2$ (comunidade). A partir da análise das palavras e segmentos de texto dessa classe, pôde-se observar que ela contempla os trabalhos de pesquisa sobre tempo livre e velhice, família e relação pessoa-ambiente. De fato, esses resultados evidenciam as linhas de pesquisa desenvolvidas por três laboratórios de pesquisa do PPG-Psi, os quais são brevemente descritos a seguir.

O Laboratório de Estudos sobre Ócio, Trabalho e Tempo Livre (OTIUM), que tem como objetivo articular a partir de enfoques multidisciplinares os seguintes temas: tempo de trabalho, tempo livre, tempo liberado, ócio e lazer. Isso pode ser observado nos exemplos: "Reconfigurações no tempo social do idoso enlutado em um estudo qualitativo sobre luto e envelhecimento na cidade de Fortaleza-CE" (Dissertação defendida em 2015) e "Envelhecimento ativo: um estudo com idosos de um centro-dia em Fortaleza-CE" (Dissertação defendida em 2018).

O Laboratório de Estudos dos Sistemas Complexos: Casais, Familias e Comunidade (LESPLEXOS), que tem como objetivo articular pesquisa, ensino e extensão na área de estudo de casais, família e comunidade, especialmente no que se refere a uma visão sistêmica destes. Produzir conhecimento contextualizado acerca desses temas, articulando sempre com a realidade das políticas sociais, dos serviços de atendimento e aos contextos de vulnerabilidade social. Exemplos de trabalhos nesta perspectiva: "Percepção de pais e filhos na vivência de limites em famílias de classe média de Fortaleza" (Dissertação defendida em 2010) e "Pessoas com deficiência e resiliência familiar: um estudo sobre os fatores de risco e proteção" (Tese defendida em 2018).

O Laboratório de Estudos das Relações HumanoAmbientais (LERHA) tem como objetivo estudar as inter-relações pessoa e ambiente, consideradas a partir das múltiplas dimensões do contexto - físicas, psicossociais, culturais, econômicas e políticas. A natureza multidisciplinar destes estudos visa dar conta da complexidade do mundo real, local privilegiado de pesquisas a partir do enfoque teórico da Psicologia Ambiental. Trabalhos nessa linha de pesquisa podem ser observados nos exemplos a seguir: "O significado da casa para moradores de habitações precárias em uma comunidade urbana de Fortaleza-CE" (Dissertação defendida em 2014) e "Experiências de um bairro em transformação: a relação pessoa-ambiente nas narrativas de antigos moradores do centro de Fortaleza" (Dissertação defendida em 2018).

\section{Classe 4 - Estudos sobre Trabalho}

Esta classe compreende $21,9 \%$ (80 ST) do corpus total analisado. Constituída por palavras e radicais no intervalo entre $\chi^{2}=83,4$ (professor) e $\chi^{2}=4,3$ (estudante). A partir da análise das palavras e segmentos de texto dessa classe, pôde-se observar que ela contempla predominantemente os trabalhos de pesquisa desenvolvidos pelo Laboratórios de Estudos do Trabalho (LET). Esse laboratório tem como objetivos: investigar as condições de trabalho e saúde de trabaIhadores formais e informais; analisar as mudanças no mundo do trabalho e suas repercussões na vida e na 
saúde do trabalhador; e identificar os fenômenos psicossociais relacionados ao trabalho. Exemplos de produções dessa classe são expostos a seguir: "Psicologia, saúde e trabalho: um estudo sobre a atuação dos psicólogos no campo da saúde do trabalhador" (Dissertação defendida em 2007) e "A influência da cultura da organização e contexto de trabalho das instituições de ensino superior no prazer e sofrimento do professor" (Tese defendida em 2017).

\section{Classe 2 - Estudos em Psicanálise}

Esta classe compreende 20\% (73 ST) do corpus total analisado. Constituída por palavras e radicais no intervalo entre $\chi^{2}=142,4$ (Psicanálise) e $\chi^{2}=4,1$ (autismo). A partir da análise das palavras e segmentos de texto dessa classe, pôde-se observar que ela contempla uma linha de pesquisa desenvolvida dentro do Laboratório de Estudos sobre Psicanálise Cultura e Subjetividade (LAEPCUS). Esse laboratório tem como objetivo atualizar e produzir pesquisas e estudos que articulem campos cruciais na consideração do sujeito, sua inscrição e constituição no laço social tomando como referenciais teóricos principais a Psicanálise e a perspectiva foucaultiana de apreensão do sujeito nas relações de saber e poder. Exemplos de trabaIhos nessa classe são trazidos a seguir. "Os fundamentos da clínica psicanalítica com criança: um estudo de caso sobre os impasses na relação mãe-criança e suas consequências na constituição psíquical" (Dissertação defendida em 2014) e "O que pode o psicanalista na assistência social: considerações a partir da escuta de adolescentes" (Dissertação defendida em 2018).

\section{Classe 3 - Estudos sobre Modos de Subjetivação}

Esta classe compreende 13,7\% (50 ST) do corpus total analisado. Constituída por palavras e radicais no intervalo entre $\chi^{2}=50,6$ (Subjetivação) e $\chi^{2}=3,9$ (gênero). A partir da análise das palavras e segmentos de texto dessa classe, pôde-se observar que ela contempla uma linha de pesquisa desenvolvida dentro do LAEPCUS a partir da perspectiva foucaultiana. Exemplos dessa classe são: "As manifestações de junho de 2013 no Brasil: discursos e modos de subjetivação sob a perspectiva de Foucault" (Dissertação defendida em 2016) e "A normatização do sujeito anormal: os efeitos da ampliação e generalização da Psiquiatria sobre os modos de subjetivação na contemporaneidade" (Tese defendida em 2016).

\section{Classe 5 - Estudos sobre Fenomenologia Clínica}

Esta classe compreende 15,6\% (57 ST) do corpus total analisado. Constituída por palavras e radicais no intervalo entre $\chi^{2}=125,8$ (fenomenológico) e $\chi^{2}=3,9$ (corpo). Verifica-se que ela representa os trabalhos de pesquisa desenvolvidos pelo Laboratório de Psicopatologia e Clínica Humanista-Fenomenológica (APHETO). Esse laboratório tem como objetivo desenvolver atividades de pesquisa, ensino e extensão em psicopatologia e clínica, a partir da lente humanista-fenomenológica. As pesquisas desenvolvidas em fenomenologia clínica utilizam uma perspectiva crítico-cultural, que busca compreender, formar pesquisadores e propor estratégias de intervenção nos diversos campos clínicos. Exemplos dessa classe são expostos a seguir: "A experiência vivida por mulheres que se submeteram à cirurgia bariátrica acompanhadas em psicoterapia humanista fenomenológica" (Dissertação defendida em 2008) e "A experiência da escrita criativa: uma compreensão fenomenológico existencial a partir de Jean Paul Sartre" (Dissertação defendida em 2018).

Cabe salientar que apenas dois laboratórios de pesquisa não apareceram claramente nos resultados, visto terem surgido nos últimos anos e estarem formando seus primeiros mestres e doutores. São o Laboratório de Estudos sobre Processos de Exclusão Social (LEPES) e o Laboratório de Estudos e Práticas em Psicologia e Saúde (LEPP-Saúde).

O LEPES foi criado em 2015 e tem como objetivo desenvolver pesquisas e intervenções no campo do preconceito. As principais linhas de pesquisa são: análise dos diferentes tipos e formas de expressão do preconceito contra minorias sociais, impacto da exclusão social em aspectos psicossociais da vida dos indivíduos e processos de legitimação das desigualdades sociais.

O LEPP-Saúde foi criado em 2016 e tem como objetivo articular ensino, pesquisa e extensão na Psicologia com interface em Saúde e Políticas Públicas. Em uma perspectiva interdisciplinar, pretende agregar conhecimento técnico-científico nos três níveis de atenção em saúde - primária, secundária e terciária, especialmente sobre as temáticas de interesse social amplo.

\section{Estudo 2. Desafios enfrentados pelos professores de uma Instituição Privada de Pós-Graduação no Nordeste brasileiro}

Este estudo teve como objetivo conhecer as percepções dos professores do PPG-Psi da Unifor acerca dos desafios que enfrentam no cotidiano da sua atuação docente em uma instituição privada no Nordeste brasileiro. 
Desafios e perspectivas de um Programa de Pós-Graduação em Psicologia de uma instituição privada no Nordeste brasileiro

\section{Método}

\section{Participantes}

Fizeram parte dessa pesquisa 10 professores do PPG-Psi dos 14 professores que compõem o corpo docente permanente do programa.

\section{Instrumento}

Esses participantes responderam a uma única pergunta disparadora: "Para você, professor de uma instituição privada no Nordeste brasileiro, quais os principais desafios que você tem se deparado na sua atuação?".

\section{Procedimento de Coleta dos Dados}

Todos os 14 professores permanentes do PPG-Psi receberem um e-mail da coordenação do programa convidando-os a participar de uma pesquisa. Na ocasião, além da pergunta, foi informado que a pesquisa faria parte da construção de um manuscrito sobre o PPG-Psi da Unifor e salientou-se o caráter voluntário e anônimo da participação deles.

\section{Procedimento de Análise dos Dados}

Todas as respostas foram copiadas para um único arquivo de texto e cada participante foi identificado apenas por um número, criando um corpus para a análise. As respostas foram tratadas com base na análise de conteúdo temática (Minayo, 2014), realizada por duas autoras desse trabalho que atuaram como juízas de modo independente. Esse procedimento se iniciou com a leitura flutuante das respostas e a identificação preliminar dos núcleos de sentido. Em seguida, a partir da exploração do material, as juízas definiram, de forma independente, categorias para a organização das respostas. Finalmente, as categorias criadas foram nomeadas e interpretadas conjuntamente pelas juízas.

\section{Resultados e discussão}

Em relação aos resultados da análise de conteúdo, as juízas chegaram à conclusão consensual de que existem três grandes categorias. As duas primeiras (o imperativo econômico que rege as instituições de ensino superior privadas e o preconceito contra uma pós-graduação privada) relacionam-se aos desafios enfrentados pelos docentes, já a terceira categoria (as boas condições de trabalho) valoriza um aspecto positivo trazido pelos docentes, quando da apresentação dos desafios vivenciados.

\section{O Imperativo Econômico que Rege as Instituições de Ensino Superior Privadas}

Esta categoria esteve presente na fala de nove professores (90\%) e reúne respostas sobre duas subcategorias: política deficitária de captação e retenção de alunos e a lógica de mercado que rege as relações de trabalho e a produção de conhecimento. Sobre a primeira subcategoria, os professores referem-se às dificuldades de ter que lidar com um aluno que, na maioria das vezes, para arcar com a mensalidade do curso e se manter financeiramente, precisa conciliar seu trabalho de mestrado ou doutorado com outras atividades profissionais, o que interfere na qualidade do tempo dedicado ao trabalho acadêmico. Isso pode ser observado nas falas a seguir:

Sem sombras de dúvidas, o principal desafio é lidar com o fato de os alunos terem que pagar um valor considerável para fazer um mestrado ou doutorado. Muitas vezes, formamos alunos na iniciação científica, mas quando eles se formam vão tentar fazer mestrado e doutorado em instituições públicas, onde não têm que desembolsar uma quantia considerável e ainda por cima tem a chance de concorrer a uma bolsa. O fato de os alunos pagarem para fazer uma pós-graduação acarreta outros desafios. A maioria deles precisa conciliar o mestrado ou o doutorado com outro trabalho, o que acarreta um menor tempo e energia para se dedicar ao trabalho acadêmico. (Participante 7)

As bolsas de mestrado e doutorado não atendem à maioria dos alunos(as) e, quando existentes, possuem critérios que não se aplicam ao nosso público, como por exemplo, a demanda de que o(a) bolsista tenha dedicação exclusiva e não possa trabalhar. Ademais, o valor da bolsa não é suficiente para cobrir a mensalidade cobrada... Esse imperativo econômico reverbera na busca de alunos pela seleção...(Participante 8)

Algumas vezes, as questões econômicas se sobrepujam, tais como dificuldades financeiras do discente, financiamentos, entre outros. É isso, queria dizer, que apontei os desafios não me sentindo vítima do sistema, mas com vontade de falar claramente e com coragem, que a economia faz parte de nossa vida acadêmica.(Participante 1)

Salienta-se que outro aspecto relacionado à dimensão econômica, que deixa mais evidente a necessidade de uma política de captação e retenção na pós-graduação privada, diz respeito à "fuga" de alunos, genuinamente interessados nas temáticas e linhas de pesquisa de docentes do PPG-Psi, inclusive por já terem 
sido alunos de iniciação científica, para instituições públicas, visando cursar o Mestrado e/ou Doutorado. Sistematicamente, os professores referem ter que conviver com essa realidade, fato que por eles é considerado negativo, sobretudo considerando que muitos já estariam melhor formados academicamente para cursarem a pós-graduação.

A esse respeito, uma política institucional que promova um maior número de bolsas de Mestrado/ Doutorado (de financiamento público, mas também privado), assim como uma reformulação na proposta de concessão de bolsas (com a não condicionalidade de não poder trabalhar); e uma oferta de financiamento para o ensino privado, à semelhança do Fundo de Financiamento ao Estudante do Ensino Superior (FIES), poderia constituir uma alternativa para essa situação e incrementar a participação de alunos(as) no processo seletivo do PPG-Psi.

Sobre a segunda subcategoria, observam-se falas que reconhecem outra dimensão desafiadora com a qual os professores se deparam cotidianamente na sua atuação. A lógica de mercado que perpassa a sua/nossa prática. Isso pode ser observado nas falas a seguir:

Há, contudo, um tipo de funcionamento interno, administrativo e político muito próprio de uma instituição privada, que dificulta o progresso de uma lógica acadêmica. A instalação de uma forma empresarial, muito afeita ao discurso e às políticas neoliberais, entravam o entendimento de que a produção acadêmica não responde necessariamente, nem diretamente, às demandas de mercado; pelo menos no campo da psicologia. Por mais que estejamos ainda, um tanto protegidos desse funcionamento aqui na Unifor, considero que há o risco desse discurso se expandir e criar obstáculos, ou pretender adaptar o funcionamento acadêmico à lógica empresarial. (Participante 5)

Os trechos supracitados retratam uma preocupação bastante atual dos docentes no que diz respeito à necessidade de produção de conhecimento que atenda às demandas de mercado e produza uma "inovação" que venha a se reverter em injeção de capital para a instituição (Mancebo, 2010) e, consequentemente, desenvolvimento de produtos e patentes, que possam ser comercializados. Ambas as falas ressaltam, no entanto, a especificidade do PPG-Psi - vinculado à área das Ciências Humanas e Sociais - e que, não necessariamente, tem essa vocação para o desenvolvimento de produtos que possam ser comercializados. É importante mencionar que tal lógica tem invadido não apenas instituições privadas, mas também a política da pós-graduação como um todo e, inclusive, as instituições públicas, criando uma falsa hierarquia de valor (e subsídio) entre as chamadas hard e soft sciences.

Outro aspecto salientado pelos docentes nessa categoria diz respeito à falta de estabilidade no emprego, característica das relações de trabalho em instituições privadas, tal como afirma o Participante 6: "A instituição privada possui um aspecto delicado que é o da não estabilidade do professor." Diferentemente do que ocorre em instituições públicas, a permanência de um docente, não apenas no programa de pós-graduação, mas na instituição, está diretamente relacionada à sua produção acadêmica e científica. Como aponta Mancebo (2010), esse aspecto financeiro rege "um padrão produtivista e um tipo de 'cultura do desempenho', sob a qual o trabalho docente é permanentemente pontuado, traduzido em números e intensificado através de diversos e complexos sistemas de avaliação..." (p. 83).

\section{O Preconceito Contra uma Pós-Graduação Privada}

Esta categoria esteve presente na fala de oito professores (80\%) e reúne comentários sobre o preconceito que os professores dizem sentir da parte de outros colegas de profissão e da própria política acadêmica que tende a conferir ao trabalho desenvolvido por professores de programas de pós-graduação de instituições privadas um lugar inferior e de menor relevância na produção do conhecimento científico. Isso pode ser observado nas falas a seguir:

Como professora de uma instituição universitária privada posso dizer que enfrento duas ordens de desafios: de um lado, referente à academia, à política acadêmica, à divisão entre públicas e privadas, como base de legitimação e reconhecimento do trabalho científico... Sob as expectativas acadêmicas, trabalhamos para que nossas pesquisas e artigos tenham relevância científica e social, apesar da opinião hegemônica no mundo acadêmico, publicamente manifesta, que nas universidades privadas não existe pesquisa e que 'os professores são trabalhadores explorados'.(Participante 1)

Desafios quanto ao reconhecimento por parte das instâncias fomentadoras (CAPES, CNPQ, FUNCAP etc.),quando as mesmas diferenciam incentivos para as instituições privadas; quanto aos colegas de pós-graduação, que ainda confundem-nos como professores de instituições públicas, como se não houvesse pesquisas aqui, etc. (Participante 6)

Outro grande desafio, provavelmente o mais difícil de sanar, é o preconceito que sofro pelos colegas de 
outras instituições pelo fato de eu estar numa instituição privada. É como se o mero fato de eu trabalhar numa instituição privada fizesse de mim uma profissional menos competente e capacitada para estar na pós-graduação. O preconceito é real! Ele faz com que os colegas acreditem que não existem pesquisadores de alto nível nessas instituições, ele desqualifica e diminui colegas. E ele pode ser facilmente constatado quando se observa quem são os pesquisadores que estão nos cargos de gestão e coordenação da pós-graduação brasileira. É como se o pesquisador de uma instituição privada não tivesse o direito de ocupar esses espaços. (Participante 7)

Esses relatos destacam a percepção dos docentes acerca do preconceito que vivenciam por estarem vinculados a uma instituição privada. Tal preconceito é expresso de diferentes formas, desde a falta ou pouco reconhecimento dos pares acerca da qualidade da pesquisa desenvolvida na instituição privada e dos(as) pesquisadores(as) que ali existem; passando pela percepção de um certo "protecionismo" das agências de fomento e avaliadoras; e a desigual participação de representantes de instituições privadas em comissões/gestão da pós-graduação em psicologia no Brasil. Reconhece-se, no entanto, que esse preconceito não é vivido na passividade e sem que haja enfrentamentos. Dessa forma, entende-se que o reconhecimento de sua existência tem sido um primeiro passo para busca de ações afirmativas e lutas por espaço, as quais certamente podem ser (mais) vistas no atual cenário da pós-graduação.

A esse respeito, a fala do Participante 5, é bastante ilustrativa de qual lugar imaginamos a complementaridade dos papéis sociais desempenhados por instituições públicas e privadas na pós-graduação brasileira.

Entretanto, há uma cultura no Brasil, da qual não discordo completamente, de valorização das instituições públicas, o que se reflete tanto no reconhecimento como nas políticas públicas de fomento à pesquisa, às bolsas, etc. Enfrentamos, além da dificuldade e do preconceito regional - que existe e se manifesta por vezes diretamente, na fala dos colegas, por outras na concessão desses fomentos suportamos a condição de trabalhar em uma instituição privada. São dois significantes que têm peso: instituição privada e nordestina. Importante valorizar as instituições e o ensino público, mas não em detrimento de uma faceta deste ensino. (Participante 5)

Tal complementaridade tem relação com o reconhecimento da relevância científica e social da instituição privada, exemplificadas na formação de mestres e doutores e, sobretudo, na produção de conhecimento científico, o qual está devidamente comprometido ética e politicamente com a ciência psicológica e a sociedade como um todo: "Sob as expectativas acadêmicas, trabalhamos para que nossas pesquisas e artigos tenham relevância científica e social... Formamos muitos doutores e mestres e produzimos conhecimentos, por conseguinte, temos responsabilidades com a ciência e com a sociedade." (Participante 1).

\section{Boas Condições de Trabalho}

Esta categoria esteve presente na fala de quatro professores (40\%) e destoa das anteriores por enfatizar um aspecto positivo da atuação em uma instituição privada, qual seja, a existência de boas condições de trabalho. Dentre os aspectos citados pelos docentes como estando relacionados às boas condições de trabalho, citam-se a infraestrutura de qualidade, a existência de fomentos à pesquisa, prêmios de produtividade para os docentes, dentre outros, conforme se pode ver a seguir:

Trabalhar em uma instituição particular de grande porte, e com muitos recursos, permite facilidades que a maioria dos professores de outras instituições não possuem: infraestrutura física fantástica; gabinetes individuais para professores; gráfica para impressão de provas, trabalhos, banners e questionários de pesquisas; e incentivo financeiro de pesquisa - seja de bônus ao professor, seja de financiamento de projetos, e bolsas adicionais de iniciação científica. (Participante 2)

Além das boas condições de trabalho, relacionadas aos aspectos supracitados, destaca-se a consciência dentre o corpo docente e entre a comunidade científica brasileira - de que a Unifor, enquanto instituição privada, tende a se diferenciar de outras instituições privadas. Tal diferenciação, em termos qualitativos, está relacionada a alguns fatores: à existência do Programa de Pós-graduação em Psicologia (PPG-Psi); ao protagonismo desse PPG no Estado e na região Nordeste; à edição de uma revista científica de reconhecida qualidade entre os pares; à exigência de oito horas semanais na graduação para cada professor vinculado à pós-graduação, quantitativo considerado satisfatório em comparação a outras instituições públicas e mesmo privadas; e, por fim, à abertura da instituição para a realização de eventos nacionais e internacionais de relevância na área, sem que para isso seja exigida nenhuma contrapartida financeira das entidades organizadoras. Nos últimos anos, por exemplo, a Unifor sediou a realização de importantes eventos como XIII Simpósio Nacional da ANPEPP (2010), $\checkmark$ Conferência Internacional de Psicologia Comunitária (2014) e 46ª Reunião Anual da Sociedade Brasileira de

Estudos de Psicologia, 24(2), abril a junho de 2019, 159-170 
Psicologia (2016), os quais foram todos muito bem avaliados dentre os participantes.

É, portanto, evidente entre os docentes do PPG-Psi o reconhecimento do apoio obtido por parte da instituição para a realização de iniciativas que visam integrar a comunidade científica da Psicologia, no caso de eventos nacionais e internacionais, mas também no nível local - favorecer a interação da comunidade acadêmica com serviços e instituições da cidade de Fortaleza e região. A esse respeito, citam-se as múltiplas atividades de inserção social desenvolvidas pelo PPG-Psi e seus laboratórios, com a presença de profissionais das áreas de educação, saúde, assistência social, segurança pública, etc. intramuros e extramuros.

\section{Considerações finais}

O artigo buscou apresentar o Programa de Pós-graduação em Psicologia (PPG-Psi) da Universidade de Fortaleza (Unifor), discutindo desafios e perspectivas da sua existência, enquanto um programa de uma instituição privada, no Nordeste brasileiro. Para isso foram realizados dois estudos empíricos que tiveram como objetivos, respectivamente, traçar um panorama das pesquisas desenvolvidas no programa e analisar as percepções dos professores do programa acerca dos desafios que enfrentam no cotidiano de trabalho docente.

Entende-se que é fundamental reconhecer o pioneirismo do PPG-Psi na pós-graduação em Psicologia no Estado do Ceará e na região Nordeste, bem como a sua grande relevância na formação de mestres e doutores, os quais têm contribuído significativamente para a formação de novos profissionais (principalmente psicólogos) em outras IES. A formação de recursos humanos para a pesquisa e para a docência no Ensino Superior, portanto, tem sido uma importante tarefa que o PPG-Psi vem cumprindo ao longo da sua história.

A diversidade de dissertações e teses defendidas reflete a pluralidade teórica e metodológica que é característica do Programa, a qual transita de abordagens mais clínicas (psicanálise e fenomenologia) até os estudos da psicologia social, psicologia do trabalho, psicologia do desenvolvimento, psicologia da saúde e psicologia ambiental. Tal pluralidade, por sua vez, é muito bem ilustrada na existência dos oito laboratórios de pesquisa e dos 14 docentes permanentes que constituem o Programa. Além disto, tende a ser vista sempre como uma fortaleza do programa e não o contrário.

Dentre os desafios apontados pelos docentes do PPG-Psi como inerentes à sua condição de docentes de uma instituição privada foram citados o imperativo econômico que rege tais instituições, bem como o preconceito que sofrem. Esses resultados são extremamente importantes para se pensar a especificidade de um programa deste tipo, o qual - a despeito do preconceito vivido - responde tanto quanto uma instituição pública - por seus feitos, sendo avaliado sob os mesmos critérios. Por fim, verificou-se que os docentes, ao mesmo tempo em que destacaram os desafios acima, tenderam a valorizar as boas condições de trabalho que possuem na Unifor, reconhecendo o lugar diferenciado que esta instituição possui dentre outras de natureza semelhante.

Diante destes resultados, considera-se que algumas importantes perspectivas de futuro podem ser delineadas. Porém, é preciso que se considere que - politicamente - o ensino superior e a pós-graduação vivem um momento crítico de sua história, marcado por ações bastante negativas por parte do atual Governo Federal, que vão da redução/corte dos orçamentos à violência simbólica com tudo aquilo que se diz científico; mobilizando a opinião pública contra as Universidades, pesquisadores e alunos, mas também com políticas de muito retrocesso no tocante à garantia de direitos sociais, especialmente, das minorias. Tais ações já impactam as instituições públicas e, em maior ou menor grau, as instituições privadas, já que estas também contam com financiamento público.

Portanto, pensar as perspectivas para o futuro da pós-graduação em uma instituição privada é especialmente complicado e exigente nesse cenário. No entanto, considera-se que há perspectivas de atuação que são mais internas à instituição em si; e outras, mais externas, embora ambas estejam intrinsecamente relacionadas. Externamente, reconhece-se a urgente necessidade da luta/militância pela defesa do direito à educação no nível superior e à pós-graduação, seja ela pública ou privada. Ocupar os espaços políticos de decisão e contribuir para a formação da opinião pública, em defesa do ensino superior e da pós-graduação, são tarefas de primeira ordem. Também externamente, considera-se como importante seguir contribuindo para o aumento da visibilidade das pesquisas e intervenções realizadas no PPG-Psi, o que passa pela publicação científica em veículos de reconhecida qualidade e pela participação dos docentes em redes de pesquisa, entidades da Psicologia e órgãos e agências de fomento.

No nível mais interno, institucional, a perspectiva de atuação parece ser o de seguir mostrando indicadores de produtividade e impacto social, que coloquem o nome da instituição em lugar de destaque. Assim como, 
trabalhar para aumentar perspectivas na política de financiamento estudantil (bolsas, editais, descontos, etc.) por parte da própria instituição, que venha a fomentar o ingresso de alunos interessados no Programa.

Ao corpo docente e discente caberá discutir e encontrar caminhos para continuar garantindo (e aumentar) o seu papel de relevância social e científica, sobretudo a partir dos indicadores pelos quais o Programa é constantemente avaliado. Entende-se esse movimento como processual e, sobretudo, como algo que pode levar o Programa a patamares de maior destaque. Finalmente, é fundamental que se esclareça que - o maior destaque aqui pretendido - diz respeito à produção de um conhecimento cientificamente relevante e, além disso, social e politicamente comprometido com a garantia de direitos dos grupos e populações com as quais trabalhamos.

\section{Referências}

Bastos, A. V. B., Tomanari, G. Y., \& Trindade, Z. A. (2017). Relatório Quadrienal 2017 - Psicologia. Recuperado de https://capes.gov. br/images/documentos/Relatorios_quadrienal_2017/20122017Psicologia_relatorio-de-avaliacao-2017_final.pdf

Camargo, B. V., \& Justo, A. M. (2018). Tutorial para uso do software IRAMUTEQ (Tutorial for Using the IRAMUTEQ Software). Recuperado de http://www.iramuteq.org/documentation/fichiers/Tutorial\%20 IRaMuTeQ\%20em\%20portugues_17.03.2016.pdf
Conselho Federal de Educação. (1965, 03 dezembro). Parecer $n^{\circ}$ 977/65. Definição dos cursos de pós-graduação. Brasília, DF: Autor. Recuperado de http://www.ccpg.puc-rio.br/nucleodememoria/ textosfinais/parecerCFE97765.pdf

Coordenação de Aperfeiçoamento de Pessoal de Nível Superior - CAPES. (2004). Plano nacional de pós-graduação (PNPG), 2005-2010. Brasília: MEC. Recuperado de https://www.capes.gov.br/images/ stories/download/editais/PNPG_2005_2010.pdf

Féres-Carneiro, T., Bastos, A. V., Feitosa, M. Â. G., Seidl-de-Moura, M. L., \&Yamamoto, O.H. (2010). Lacunas, metas e condições para expansão da pós-graduação em psicologia no país. Psicologia: Reflexão e Crítica, 23(Supl. 1), 11-24. doi: 10.1590/S0102-79722010000400003

Mancebo, D. (2010). Trabalho docente na educação superior brasileira: mercantilização das relações e heteronomia acadêmica. Revista Portuguesa de Educação, 23(2), 73-91. doi: 10.21814/rpe.13987

Minayo, M. C.S. (2014). O desafio do conhecimento: pesquisa qualitativa em saúde (14aㅡ ed.). São Paulo: Hucitec.

Tomanari, G. A.Y., Santos, A. A. A., \& Mourão, L. (2019). Documento de Área - Área 37: Psicologia. Recuperado de

https://capes.gov.br/images/Documento_de_\%C3\%A1rea_2019/ PSICOLOGIA.pdf

Tourinho, E. Z., \& Bastos, A.V.B. (2010). Challenges to graduate courses in psychology in Brazil. Psicologia: Reflexão e Crítica, 23, 35-46. doi: 10.1590/S0102-79722010000400005

Yamamoto, O. H. (2006). Graduação e pós-graduação em psicologia: relações possíveis. Revista Brasileira de Pós-Graduação, 3(6), 270-281. doi: 10.21713/2358-2332.2006.v3.110

Yamamoto, O. H., \& Tourinho, E. Z. (2007). Documento da Área da Psicologia - Relatório Final da Avaliação Trienal 2007. Recuperado de https://www.capes.gov.br/images/stories/download/avaliacao/ RelatorioAvTrienal_PSICOLOGIA_2007.pdf

\footnotetext{
1. Retirado de: https://www.unifor.br/web/pos-graduacao/mestrado-psicologia

2. Retirado de: https://www.unifor.br/web/pos-graduacao/doutorado-psicologia
}

Normanda Araujo de Morais, Doutora em Psicologia pela Universidade Federal do Rio Grande do Sul - UFRGS, Pós-doutora em Psicologia pela Universidade Federal do Rio Grande do Sul - UFRGS, é Professora Titular da Universidade de Fortaleza - UNIFOR. Endereço para correspondência: Programa de Pós-graduação em Psicologia, Avenida Washington Soares, 1321, bairro Edson Queiroz. CEP: 60.811-905. Telefone: (85) 3477-3217. Email: normandaaraujo@gmail.com

Luana Elayne Cunha de Souza, Doutora em Psicologia Social pela Universidade Federal da Paraíba - UFPB, é Professora Adjunta da Universidade de Fortaleza - UNIFOR. Email: luana_elayne@hotmail.com

Luciana Maria Maia, Doutora em Psicologia Social pela Universidade Federal da Paraíba - UFPB, é Professora Titular da Universidade de Fortaleza - UNIFOR. Email: lumariamaia@hotmail.com

Leônia Cavalcante Teixeira, Doutora em Saúde Coletiva pelo Instituto de Medicina Social da Universidade do Estado do Rio de Janeiro - UFRJ, Pós-doutora em Psicologia pela Universidade Aberta de Lisboa - UAL, é Professora Titular Universidade de Fortaleza - UNIFOR. Email: leonia.ct@gmail.com 